\title{
Manejo de resíduos de serviços de saúde em uma Unidade Básica de Saúde vinculada a uma Instituição de Ensino Superior
}

\author{
Waste management of health services in a Basic Health Unit \\ linked to an Institution of Higher Education \\ Catia Suelem Manke Vieira, Mateus Torres Nazari, Carolina da Silva Gonçalves e \\ Luciara Bilhalva Corrêa \\ Universidade Federal de Pelotas, Pelotas, RS, Brasil \\ suelemmanke@gmail.com; nazari.eas@gmail.com; carolzitasg@gmail.com; luciarabc@gmail.com
}

\begin{abstract}
Resumo
Quando gerenciados de forma inadequada, os resíduos provenientes de serviços de saúde impactam negativamente o ambiente, causando riscos à saúde pública e degradação ambiental, devido suas características físicas, químicas e patogênicas. Com base na legislação vigente, analisou-se o processo de gestão dos resíduos de serviços de saúde (RSS) em uma Unidade Básica de Saúde (UBS) vinculada a uma Instituição de Ensino Superior (IES), visando fornecer ferramentas técnicas para proposição de um Plano de Gerenciamento de Resíduos de Serviços de Saúde (PGRSS). Por tratar-se de uma pesquisa qualitativa, empregou-se como instrumento de coleta de dados a observação participante, buscando mostrar a realidade percebida e, principalmente explicitar não conformidades observadas durante as etapas do gerenciamento dos RSS (segregação, acondicionamento, coleta interna, transporte, armazenamento e coleta externa). Para tanto, utilizou-se a metodologia estabelecida pela ANVISA (2006), a qual é baseada em uma ordem de prioridades distribuídas através de uma organização das etapas de trabalho. Ao final do estudo, foi possível constatar irregularidades na UBS em relação ao manejo dos RSS. Nessa perspectiva, recomenda-se a elaboração, implantação e monitoramento de um PGRSS, fundamentado na resolução preconizada pela legislação vigente.
\end{abstract}

Palavras-chave: Resíduos de Serviços de Saúde; Plano de Gerenciamento de Resíduos de Serviços de Saúde; Unidade Básica de Saúde.

\begin{abstract}
When not properly managed, residues from healthcare services negatively affect the environment, inducing risks to public health and environmental degradation, due to its physical, chemical and pathogenic characteristics. Based on current legislation, the management process of residues from health services (RHS) in a Basic Health Unit (BHU) linked to an Institution of College Education was analyzed, in order to provide tools to propose a Management Plan of Residues from Health Services (MPRHS). As it was a qualitative research, the instrument used to collect the data was the participant observation, seeking to show the reality as it is perceived and, mainly, clarify the non-compliances observed during the management stages of RHS (segregation, packaging, internal collection, transport, storage and external collection). Therefore, it was used the methodology established by ANVISA (2006), which is based on an order of priorities distributed through an organization of work steps. At the end of this study, it was possible to determine irregularities in BHU regarding to the management of RHS. In this perspective, it is recommended elaboration, implementation and monitoring of a MPRHS, based on the resolution recommended by the current legislation.
\end{abstract}

Keywords: Health Services Residues; Management Plan of Health Services Residues; Basic Health Unit. 


\section{Introdução}

De acordo com Farias (2005), a geração de resíduos relaciona-se intimamente ao grau de desenvolvimento de uma sociedade. Ao longo dos anos, tanto a variação na quantidade, quanto na qualidade dos resíduos, intensificaram a problemática existente na geração desses materiais, sendo essa variação influenciada pelos atuais padrões de produção e consumo da humanidade e à evolução do homem.

No Brasil, foi registrado em 2014 um crescimento de $2,9 \%$ na taxa de geração de Resíduos Sólidos Urbanos (RSU) em relação a 2013, sendo esse índice percentual superior à taxa de crescimento populacional urbano do país, a qual foi de 0,9\% no mesmo período. Em 2014, foram geradas 78.583.405 toneladas de RSU no Brasil. Desse total, 264.800 toneladas correspondem à geração de dos Resíduos de Serviços de Saúde (RSS), representando um aumento de 5\% comparado a 2013 no país (ABRELPE, 2015).

Dentre os RSU, a categoria RSS necessita de uma maior atenção, devido suas características físicas, químicas, biológicas e patogênicas, que conferem riscos potenciais tanto à saúde pública quanto ao meio ambiente. Diante disso, torna-se fundamental um manejo específico a esse tipo de resíduo, o qual necessita de cuidados especiais desde o momento da geração até a disposição final (SERAPHIM, 2010).

Conforme a Resolução da Diretoria Colegiada (RDC) ANVISA no 306/2004 e a Resolução do CONAMA nº 358/2005, os RSS definem-se como sendo todos os resíduos gerados nos serviços relacionados ao atendimento à saúde humana ou animal. Em relação às fontes geradoras, estas variam bastante, incluindo farmácias, clínicas odontológicas e veterinárias, assistência domiciliar, necrotérios, instituições de cuidado para idosos, hemocentros, laboratórios clínicos e de pesquisa, instituições de ensino, unidades básicas de saúde, entre outros (BRASIL, 2004; BRASIL, 2005).

Segundo a RDC da ANVISA n 306/04, os RSS devem ser classificados conforme suas características físicas, químicas, biológicas, origem e estado da matéria, com objetivo de realizar o gerenciamento e manejo adequado desses resíduos. De acordo com as resoluções da Agência Nacional de Vigilância Sanitária (ANVISA) RDC nº 306/2004 e do Conselho Nacional do Meio Ambiente (CONAMA) no 358/2005, os RSS são classificados em 5 grupos: No Grupo A incluem-se os resíduos biológicos; no Grupo B, resíduos de origem química; no Grupo C, rejeitos radioativos; no Grupo D, resíduos comuns; e, no Grupo E, os materiais perfurocortantes (BRASIL, 2004; BRASIL, 2005).

Conforme a RDC n 306/2004 da ANVISA, o gerenciamento de RSS é caracterizado como sendo um conjunto de procedimentos de gestão, planejados e implementados a partir de bases científicas e técnicas, normativas e legais, com o objetivo de minimizar a produção de resíduos e proporcionar aos resíduos gerados, um encaminhamento seguro, visando à preservação da saúde pública e do meio ambiente (BRASIL, 2004).

De acordo com a Lei 12.305/2010, a qual institui a Política Nacional de Resíduos Sólidos (PNRS), a destinação ambientalmente adequada dos resíduos, incluindo os RSS, deve observar normas operacionais específicas, com o objetivo de evitar danos ou riscos à saúde pública e à segurança, além de minimizar os impactos ambientais adversos (BRASIL, 2010). Tendo em vista que os RSS apresentam potencial de contaminação e risco ambiental, mostra-se imprescindível um gerenciamento adequado, eficiente e responsável desses materiais por parte dos geradores, tanto nas etapas realizadas dentro do estabelecimento (segregação, acondicionamento, transporte, armazenamento, tratamento), quanto nas etapas extras (transporte, armazenamento, tratamento e disposição final) (SCHNEIDER et al., 2004). Para tanto, torna-se necessário um estudo quantitativo e qualitativo para caracterizar os resíduos gerados para implementação de um PGRSS efetivo (BARROS et al., 2007)

Para minimizar os impactos causados pela má disposição destes resíduos, políticas públicas e legislações vêm se tornando um eixo de orientação à sustentabilidade do meio ambiente e a preservação da saúde. Focado neste objetivo, órgãos como a Agência Nacional de Vigilância Sanitária (ANVISA) e o Conselho Nacional do Meio Ambiente (CONAMA) têm assumido o papel de orientar, definir regras e regular a conduta dos diferentes agentes, no que se refere à geração e ao manejo dos RSS. A Política Nacional de Resíduos Sólidos (PNRS) também insere-se nesse contexto. Uma exigência legal imposta por estes órgãos foi o Plano de Gerenciamento de Resíduos de Serviço de Saúde (PGRSS), o qual objetiva estabelecer aos geradores um gerenciamento correto dentro das unidades de atendimento (BRASIL, 2006). Apesar das exigências legais, o PGRSS ainda não foi devidamente implantado em todos os estabelecimentos de saúde, principalmente quando se trata de pequenos geradores de RSS. Isso pode estar associado ao fato de que, em virtude de gerarem quantidades menores de resíduos, esses prestadores recebem pouca ou nenhuma atenção dos órgãos competentes de fiscalização (MOREIRA, 2012).

Até o ano de 2011, as Unidades Básicas de Saúde (UBS) somavam 38 mil unidades pelo país. Essas unidades são responsáveis pela atenção primária à população e que tem como objetivo principal atender até $80 \%$ dos problemas de saúde da população, sem que haja a necessidade de encaminhamento para hospitais. Nela são desenvolvidos atendimentos básicos como consultas médicas, inalações, injeções, curativos, vacinas, coleta de exames laboratoriais, tratamento odontológico, encaminhamentos para especialidades e fornecimento de medicação básica (PORTAL BRASIL, 2013).

Em relação à UBS pesquisada, além de colaborar para a esfera de atendimento à saúde, a unidade também conta com práticas de ensino nas áreas da saúde, o que 
contribui à formação de futuros profissionais. $O$ fomento para tais atividades de ensino é fornecido através de um vínculo com uma Instituição de Ensino Superior (IES), que provê ao estabelecimento todos os materiais necessários para o atendimento à população, bem como professores capacitados para orientar os estudantes.

Uma visão minuciosa sobre os RSS gerados neste ambiente necessita de uma análise de todas as etapas de gerenciamento destes resíduos. No âmbito de uma IES, isso se mostra necessário pelo papel educativo que esta exerce na formação de futuros profissionais, além de contribuir para a conscientização e sensibilização de todos os sujeitos envolvidos na gestão dos RSS, a fim de corroborar com o aperfeiçoamento de medidas preventivas de contaminação ambiental e ocasional gerada por estes resíduos. Nessa perspectiva, este estudo tem como principal objetivo fornecer ferramentas técnicas para a proposição de um Plano de Gerenciamento de Resíduos de Serviços de Saúde (PGRSS) em uma Unidade Básica de Saúde (UBS) vinculada a uma Instituição de Ensino Superior, visando à gestão integrada dos resíduos.

\section{Metodologia}

A presente pesquisa foi realizada no Município de Pelotas no Estado do Rio Grande do Sul - Brasil, junto a uma Unidade Básica de Saúde (UBS) vinculada a uma Instituição de Ensino Superior. Em relação ao desenvolvimento deste trabalho, utilizou-se uma abordagem qualitativa se aproximando de um de estudo de caso (MORESI, 2003).

Mediante dados coletados pela metodologia participativa, buscou-se apresentar a realidade percebida, explanando principalmente as não conformidades encontradas durante as etapas funcionais do gerenciamento dos RSS (segregação e acondicionamento, coleta interna e transporte, armazenamento e coleta externa) na UBS da IES.

Essa pesquisa foi aprovada e está presente no Certificado de Apresentação para Apreciação Ética da Universidade Federal de Pelotas sob o número 49571015.5.0000.5341.

\section{Características do Local de Estudo}

A Unidade Básica de Saúde estudada tem como objetivos básicos o ensino, a pesquisa e a assistência médica. Através de uma equipe multidisciplinar composta por médicos, enfermeiros, nutricionistas, assistente social e outros profissionais de nível técnico, o estabelecimento oferece atenção básica à saúde à população de aproximadamente dez mil pessoas, priorizando grupos de risco e situações socioeconômicas.

Juntamente com mais quatro UBSs, estas compõem uma rede de atendimento à saúde da população, fomentada através de um vínculo ao Departamento de Medicina Social da Faculdade de Medicina da IES.
Nestas unidades são desenvolvidas atividades de ensino de graduação dos cursos de Medicina (graduação e residência médica) e Nutrição.

\section{Critérios de Escolha da Unidade de Estudo}

O interesse em realizar uma avaliação do gerenciamento dos Resíduos de Serviços de Saúde (RSS) em Unidades Básicas de Saúde ocorreu por dois motivos: 1) por estas Unidades estarem vinculadas a uma IES, espaço destinado à formação de futuros profissionais responsáveis pela promoção da saúde e, dessa forma, é fundamental uma gestão de RSS adequada e segura neste âmbito, visando à manutenção da qualidade de vida; 2) devido à significância que o atendimento desse estabelecimento traz à população. Quando bem estruturadas, as UBSs conseguem reduzir filas em hospitais e prontos-socorros, uma vez que fornecem soluções aos problemas mais frequentes de saúde.

\section{Instrumentos de Coleta de Dados}

\section{Estudo Documental}

O estudo documental é uma fonte de coleta de dados considerada como uma técnica valiosa de abordagem dos dados qualitativos, a qual é utilizada tanto para complementar as informações obtidas por outros métodos, quanto para identificar aspectos novos de um tema ou problema (CORRÊA, 2009 apud LAKATOS; MARCONI, 1991).

A fim de elaborar o Plano de Gerenciamento de Resíduos de Serviços de Saúde, buscou-se, através de uma pesquisa bibliográfica, compreender a classificação dos RSS, a importância de um gerenciamento adequado nos estabelecimentos de saúde, bem como a caracterização de um processo de gestão eficaz. O conhecimento adquirido pela literatura possibilitou a identificação de problemas, através da observação de falhas ocasionadas pela falta de recursos do estabelecimento e pelo descuidado dos profissionais no ato de segregação.

\section{Observação Participante}

De acordo com Marcos (2001), a observação participante corresponde a um método, onde o pesquisador acompanha o cotidiano do grupo ou organização pesquisada, até pode desempenhar tarefas regularmente, com o intuito de entender em profundidade aquele ambiente. Através disso, foi possível registrar informações mais precisas, de modo a vivenciar o comportamento dos profissionais atuantes dentro da UBS, mostrando a real atitude imposta por eles em relação ao manejo dos RSS. Além disso, essa metodologia permitiu uma maior interação com os profissionais da área da saúde e, principalmente, com a higienizadora. As observações foram realizadas semanalmente, em dias e horários alternados, 
durante o período de seis meses.

\section{Registro dos Dados}

Para o registro das observações foi utilizado um roteiro previamente estabelecido, a fim de promover uma melhor organização dos dados obtidos a partir das visitas realizadas na UBS. Além disso, empregou-se o recurso fotográfico do ambiente de estudo, de modo a retratar as formas de acondicionamento e armazenamento dos RSS gerados na unidade.

\section{Aspectos Éticos na Pesquisa}

Estando ciente que é responsabilidade do pesquisador manter a ética em sua pesquisa, buscou-se a autorização do responsável pelas UBSs, apresentando a ele os objetivos principais do estudo. Em relação à necessidade de assegurar o anonimato das informações fornecidas pelos sujeitos da pesquisa (docentes, servidores, funcionários terceirizados), foi elaborado e entregue o Termo de Consentimento Livre e Esclarecido (TCLE) aos mesmos, no qual constava que a participação na pesquisa era voluntária e que seria disponibilizado o acesso aos resultados do trabalho.

\section{Elaboração da Pesquisa}

A partir de uma abordagem participativa e utilizando uma ferramenta simplificada e de fácil aplicação que mostrasse uma avaliação rápida da situação da UBS. Este instrumento funcionou através de uma sequência de quatro etapas (Identificação do problema; Definição da equipe de trabalho; Mobilização da organização; Diagnóstico da situação dos RSS) preconizadas pela ANVISA (2006). Com isso, foi possível observar a situação da UBS e, assim, indicar as não conformidades diante das exigências normativas da legislação, assim como obter informações necessárias para a elaboração do PGRSS da unidade.

\section{Resultados e Discussões}

De acordo com a ANVISA (2006), para elaboração de um PGRSS é necessário adotar uma sequência de oito etapas, que devem ser organizadas adequando-se às características de cada estabelecimento. São elas: 1) Identificação do problema; 2) Definição da equipe de trabalho; 3) Mobilização da organização; 4) Diagnóstico da situação dos RSS; 5) Definição de metas, objetivos, período de implantação e ações básicas; 6) Elaboração do PGRSS; 7) Implementação do PGRSS; 8) Avaliação do PGRSS. Em virtude do tempo de realização deste trabalho, abordaram-se somente as quatro primeiras etapas, as quais são apresentadas a seguir:

\section{Identificação do Problema na Fonte Geradora}

Esta primeira etapa abrange o conhecimento preliminar dos problemas decorrentes do gerenciamento incorreto dos RSS enfrentados pelo estabelecimento. A UBS estudada atende, mensalmente, aproximadamente 1200 pessoas do bairro do entorno da unidade. O prédio possui amplos e completos ambientes, tais como recepção, sala de vacinas, curativo e procedimentos, consultório pediátrico, consultório de clínica geral e ginecologia, entre outros. Além dos procedimentos médicos realizados na UBS, destaca-se a existência do Programa de Atendimento Comunitário de Saúde (PACS), que atende pessoas a domicílio por intermédio de ações dos agentes comunitários de saúde que são acompanhados e orientados por um enfermeiro.

Conforme estipulado pela RDC ANVISA no 306/04 e a Resolução CONAMA no 358/05, todo gerador deve elaborar e implantar o PGRSS. Embora esta seja uma exigência imposta por lei, observou-se que a unidade não o possui. Contudo, o estabelecimento tenta cumprir o seu papel de gerenciar os RSS conciliando as condições que lhe são oferecidas com a legislação. Os dados analisados em cada etapa de manejo dos RSS dentro da unidade mostram que existem ações visando uma melhor gestão, entretanto, ficam evidentes problemas decorrentes da falta de estrutura, recursos humanos e capacitação dos profissionais. Schneider et al., (2004) destaca que as dificuldades enfrentadas atualmente pelos estabelecimentos de serviços de saúde, bem como a falta de recursos e capacitações profissionais, devem ser superadas com criatividade, conhecimento técnico e responsabilidade por parte dos profissionais.

Percebeu-se que as falhas encontradas na etapa de segregação dos RSS ocorrem, muitas vezes, em virtude da falta de conhecimento dos estudantes em relação à gestão adequada de resíduos. Os graduandos ingressam na UBS a cada 3 meses, em grupos de aproximadamente 8 alunos, e somente na primeira aula na UBS são orientados pelos professores a respeito de como se deve proceder a separação destes materiais. Todavia, não há um esclarecimento sobre os possíveis riscos oriundos de uma segregação incorreta. Nessa perspectiva, estudos realizados por Corrêa (2005) mostram que estudantes dos cursos de Medicina Veterinária, Medicina e Enfermagem recebiam orientação em disciplinas ministradas a respeito da segregação dos RSS, no entanto a inexistência de um contato efetivo com tais resíduos originava dúvidas e inseguranças para proceder à separação dos resíduos.

A segregação dos resíduos na fonte é determinante na eficiência das demais etapas do manejo. Os grupos de RSS quando misturados, aumentam o volume, risco e tornam-se onerosos para tratar e dispor. Portanto, para o correto gerenciamento RSS, a classificação implantada em um estabelecimento gerador deve considerar a área de geração, a natureza e o potencial de risco dos resíduos, a fim de oferecer segurança e minimizar riscos 
tanto ao agente que maneja tais resíduos quanto ao meio ambiente (ELEUTÉRIO et al., 2008).

\section{Definição da Equipe de Trabalho}

Na unidade trabalham 27 funcionários, dos quais a maior parte é contratada pela UFPel e 3 por intermédio de empresa terceirizada. Ademais, circulam na UBS estudantes de graduação nas áreas de medicina e nutrição. $\mathrm{O}$ quadro de funcionários remete principalmente a cargos em áreas da saúde, não estipulando nenhum profissional responsável pelo gerenciamento dos RSS. Diante disso, o setor de enfermagem vem assumindo informalmente a responsabilidade sobre o gerenciamento dos resíduos. Este mesmo setor fica a cargo de orientar a higienizadora sobre a importância do uso dos Equipamentos de Proteção Individual (EPI's), tais como uniforme, luvas, caçados fechados e demais utensílios para a gestão dos resíduos. Assim, ficou evidente a carência por parte da empresa terceirizada responsável pelos serviços de limpeza na unidade, em capacitar seus funcionários a partir de informações sobre os riscos que uma gestão inadequada dos RSS representa.

Segundo as Resoluções 05/93 e 283/01 do CONAMA, é imprescindível a designação de um responsável técnico (gerente de resíduos) devidamente habilitado para elaboração, desenvolvimento, implantação, aplicação e avaliação de um PGRSS, bem como para fiscalização pelos órgãos de controle ambiental e da saúde de todo o processo, possibilitando, assim, uma gestão mais eficaz e permanente dos RSS dentro da UBS.

\section{Mobilização da Organização}

Esta etapa busca promover o conhecimento dos funcionários, mostrando a importância de se gerenciar corretamente os RSS. Além disso, tenta propiciar o envolvimento dos funcionários na execução, implantação e manutenção do PGRSS, através da disseminação de informações gerais e especificas sobre aspectos relevantes relacionados aos mesmos (ANVISA, 2006).

Com base na normativa da ANVISA (2006), buscou-se verificar a existência de alguma proposta de interação dos profissionais na unidade que permita o esclarecimento sobre o correto gerenciamento dos RSS. Segundo informações, somente os profissionais da área da saúde, não incluindo higienizadora, segurança e porteiro, realizam reuniões mensais onde são discutidos assuntos gerais no âmbito da UBS, onde aspectos referentes aos RSS possuem pequena relevância entre os temas discutidos. A partir disso, mostra-se necessário a elaboração de um instrumento baseado em informações educativas integradas para estas reuniões, o qual promova a concepção de novas atitudes que possam colaborar na busca de soluções para os problemas enfrentados pela unidade em relação aos RSS. Ademais, é importante estabelecer ações e estratégias visando a construção e implementação de instrumentos informativos, tanto para os profissionais quanto para os pacientes e comunidade em geral, uma vez que a unidade não fornece nenhum esclarecimento por intermédio de material informativo (manual, folders, cartazes, etc.) acerca do gerenciamento dos RSS e os riscos associados.

Diante desta discussão, considera-se necessário envolver os profissionais da UBS por meio de um programa de Educação Continuada, de maneira a capacitá-los mediante a disponibilização de informações a respeito da gestão correta dos resíduos. De acordo com a RDC ANVISA nำ 306/04 este programa visa orientar, motivar, conscientizar e informar permanentemente todos os envolvidos sobre os riscos e procedimentos adequados de manejo, de acordo com os preceitos do gerenciamento de resíduos, sendo imprescindível uma participação consciente, além da cooperação de todo o pessoal envolvido no processo de gerenciamento dos RSS (BRASIL, 2004).

\section{Diagnóstico da situação dos RSS}

O diagnóstico fornece dados essenciais para a implantação do plano de gestão por intermédio de um estudo alusivo. Com isso, é possível relatar a situação do estabelecimento em relação aos RSS. Para tanto, torna-se fundamental realizar o registro preciso e cuidadoso de todas as informações obtidas, as quais serão utilizadas posteriormente para a implantação do PGRSS na unidade. Além disso, se faz necessário o levantamento de todas as atividades do estabelecimento, com visitas às áreas administrativas, setores ou unidades especializadas (ANVISA, 2006).

\section{Geração}

Nesta unidade geram-se resíduos pertencentes aos Grupos A, B, D e E. Em virtude de não existir um registro formal e diferenciado por resíduo, estimou-se a geração em um volume total de 1 saco de 200L /dia.(tabela 1)

Segregação, Acondicionamento e Identificação

A segregação deve ser considerada uma etapa fundamental para o sucesso do gerenciamento dos resíduos, mas para tal deve ser realizada na fonte geradora, permitindo que os resíduos sejam acondicionados em embalagens e contenedores de acordo com a classificação adotada, estes acondicionadores devem ter estampado os símbolos internacionalmente conhecidos, caso as embalagens previamente identificadas não estejam disponíveis um funcionário habilitado deve proceder a identificação (OLIVEIRA, 2012). Segundo Takayanagui (2005) a segregação deve ser realizada desde a fonte geradora no instante em que os resíduos são produzidos com o complemento na identificação. A separação deve ser feita de acordo com as categorias de classificação, 
Tabela 1 - Descrição dos RSS gerados na UBS

\begin{tabular}{c|c|c}
\hline Grupo & Setores de Origem & Componentes \\
\hline A & $\begin{array}{c}\text { Sala de vacinas; Sala de curativos e } \\
\text { procedimentos; Sala de expurgo e esterilização; } \\
\text { Consultórios Pediátricos; Consultórios de } \\
\text { Clínica Geral e Ginecologia. }\end{array}$ & $\begin{array}{c}\text { Luvas, gaze, algodão, esparadrapos, } \\
\text { ataduras, materiais contendo sangue } \\
\text { ou líquido corpóreo, microrganismos } \\
\text { vivos ou atenuados, entre outros. }\end{array}$ \\
\hline B & $\begin{array}{c}\text { Farmácia; Sala de expurgo e esterilização; Sala } \\
\text { de vacinas. }\end{array}$ & $\begin{array}{c}\text { Medicamentos vencidos, resíduos de } \\
\text { saneantes e desinfetantes, resíduos } \\
\text { contendo metais pesados e outros. }\end{array}$ \\
\hline D & Não há geração & Não há geração \\
\hline Decepção; Sala de espera; Consultórios \\
& $\begin{array}{c}\text { Pediátricos; Consultórios de Clínica Geral } \\
\text { e Ginecologia; Consultório de Nutrição; } \\
\text { Banheiros; Cozinha; Farmácia; Sala de } \\
\text { Assistência Social; Sala de reuniônes; Saguão. } \\
\text { papelão, vidro, entre outros. } \\
\text { Não Recicláveis: papel sanitário, } \\
\text { fraldas descartáveis, absorventes } \\
\text { higiênicos, sobras de alimentos, entre } \\
\text { outros. }\end{array}$ \\
\hline Sala de curativos e procedimentos; Sala de \\
vacinas. & $\begin{array}{c}\text { Agulhas, escalpes, utensílios de vidro } \\
\text { contaminados quebrados, ampolas de } \\
\text { vidro e outros. }\end{array}$ \\
\hline
\end{tabular}

assim impede-se a contaminação de grande quantidade de resíduos, intensifica-se as medidas de segurança e facilita-se a ação em caso de acidentes ou emergências. Enfatizando-se a importância da conformidade com os métodos de tratamento e disposição final.

Um dos fatores que perfazem uma segregação correta é a presença de dispositivos de acondicionamentos (lixeiras) em quantidade e qualidade condizentes com os RSS gerados em cada ambiente em que estão inseridas, de modo a estar em conformidade com as normas RDC no 306/2004 da ANVISA e a Resolução nº 358/2005 do CONAMA.

Verificou-se que os resíduos pertencentes ao Grupo A são acondicionados em sacos brancos leitosos com capacidade para $15 \mathrm{~kg}$. Contudo este fato não pode ser observado na sua integridade devido à ocorrência de muitos erros no ato de segregação, ocasionados principalmente pelos estudantes que atuam como estagiários na UBS. O que pode levar a este erro é a falta de identificação nos dispositivos de acondicionamento, visto que não há simbologias ou especificações, havia somente a inscrição de "Lixo Contaminado" nos mesmos. Ademais, as lixeiras não seguem um padrão único de modelo e nem de tamanho, algumas sem fechamento na parte superior (tampas). Além destas inconformidades, mostra-se necessária a utilização de dispositivos que sigam as especificações técnicas obrigatórias da RDC $n^{\circ}$ 306/04 da ANVISA, tais como: ser resistente a punctura, ruptura, vazamento e tombamento; possuir superfície interna lisa e com os cantos arredondados; pedal para a abertura da tampa e portar o símbolo de identificação de resíduo infectante. Moreira (2012) em seu estudo em UBSs de São Paulo observou que a segregação dos resíduos pertencente ao Grupo A era dificultada pela falta de recipientes diferenciados e que, além disso, a identificação das lixeiras era inexistente, o que acabava dificultando a segregação dos resíduos, tanto pelos funcionários como pelos demais usuários.

A farmácia da UBS gera como resíduos químicos (Grupo B) medicamentos fora do prazo de validade. Conforme relato dos profissionais, os medicamentos vencidos ficam mantidos dentro de seus frascos e acondicionados em caixas de papelão e, em seguida, são armazenados na farmácia até coleta. Os medicamentos vencidos, já utilizados no atendimento, como pomadas, vaselina, entre outros, são também armazenados em seus respectivos recipientes.

Os resíduos contendo metais pesados (pilhas e baterias, lâmpadas fluorescentes e termômetros quebrados) são descartados inadequadamente no mesmo recipiente destinado a resíduos comuns. Esta prática imprópria requer o desenvolvimento de uma consciência crítica, visando mudanças de atitudes por parte dos profissionais. Ao procurar integrar ações, otimizando recursos e concepções, Moreira (2012) mostra em sua pesquisa um interesse dos funcionários de duas UBSs em constituir ações sustentáveis, através do recolhimento de pilhas e baterias, inclusive as trazidas pela comunidade, sendo estas acondicionadas em recipientes improvisados e transportadas por voluntários para postos de coleta.

No que se diz respeito aos resíduos comuns (Grupo D), observou-se que são acondicionados em lixeiras de plástico, bastantes simples, revestidas com saco preto. Da mesma forma que acontece com os demais grupos de resíduos, as lixeiras não possuem nenhuma outra simbologia, cartaz ou especificação demonstrando alguma orientação. A segregação dos resíduos pertencentes a este grupo é inexistente na UBS, os resíduos recicláveis são dispostos conjuntamente com os resíduos orgânicos. Conforme relatos, a separação dos resíduos não é efetivada devido à inexistência de coleta seletiva no bairro, além disso, não há dispositivos de acondicionamento 
em número suficiente, e condizente com a classificação através do código de cores para que o processo de segregação seja implantado.

Os perfurocortantes (Grupo E) são acondicionados em caixas rígidas, as quais possuem apenas a simbologia da própria caixa. A unidade conta com 3 caixas de acondicionamento com capacidade útil de 10 litros cada. Estas estão localizadas na sala de curativos, na sala de vacinas e no saguão. Além disso, não estão fixadas em suportes e se encontram em locais de fácil acesso. Como pode ser observada, a caixa da sala de vacinação estava situada inadequadamente sobre um banco. Muitas pessoas que desconhecem esta simbologia, principalmente pacientes crianças, podem se contaminar ao manusear tal caixa. Segundo relato de um funcionário, já ocorreu um acidente devido a essa má localização. Tal fato envolveu uma criança, que ao ter acesso ao recipiente acabou ferindo o braço com uma agulha. Estes acidentes são corriqueiros quando as condições do gerenciamento são impróprias, especialmente se tratando de profissionais que atuam nos estabelecimentos de saúde. De acordo com um levantamento dos RSS gerados na Irmandade Santa Casa de Misericórdia de São Paulo realizado por Gil (2007), aproximadamente 58,3\% dos profissionais interrogados já haviam sofrido algum tipo de acidente, sendo que $100 \%$ dos casos se tratavam de ferimentos com perfurocortantes. Além disso, foi verificado que dentro dessas caixas foram encontrados resíduos que não pertenciam a este grupo, tais como cartela de medicamento, pilhas, caixa de remédios, papel, gaze, algodão, os quais deveriam ser destinados em outros recipientes conforme suas características peculiares.

\section{Tratamento Prévio, Coleta e Transporte Interno}

Na UBS estudada, o único processo de tratamento realizado é a esterilização por intermédio de uma Estufa ou Forno de Pasteur de materiais reutilizáveis como espéculos de metal e pinças Cheron, utilizados em exames ginecológicos. No que diz respeito aos resíduos infectantes e perfurocortantes, estes não recebem qualquer tratamento intra-unidade.

A coleta interna dos resíduos do Grupo A e D é realizada 2 vezes ao dia, ao fim de cada turno, e ocorre conjuntamente com a limpeza dos ambientes. O recolhimento não é diferenciado conforme cada grupo de resíduo. Campos (1998) afirma que o manuseio dos recipientes com RSS (caixas de papelão, sacos plásticos e outros recipientes), deve ser feito por pessoal habilitado, devidamente paramentado e fazendo uso de EPI.

O transporte dos sacos plásticos por meio de carros de coleta é mais seguro para o trabalhador da limpeza do que a coleta manual, haja vista que previne acidentes com materiais perfurocortantes, que podem ter sido erroneamente descartados em sacos plásticos (MOREIRA, 2012 apud RUSHBROOK, 2005). Apesar da importância significativa proporcionada à segurança da higienizado- ra pelo uso deste equipamento, o transporte dos sacos de resíduos ocorre manualmente devido a inexistência deste carro de coleta na UBS. Abaixo estão descritas as formas que são realizadas essas etapas:

Grupo A: o saco branco leitoso, o qual contém os resíduos infectantes, é retirado e fechado através de um nó. A partir daí são removidos manualmente e armazenados em um recipiente de acondicionamento de maior capacidade, localizado na sala de expurgo e esterilização. Ao final de cada turno, os resíduos são removidos desta lixeira e levados para o armazenamento externo da UBS.

Grupo B: os medicamentos vencidos são devolvidos para os fornecedores através da (Farmácia e Hospital escola), ambos os estabelecimentos pertencentes à IES. Conforme relatos, existe certa rejeição por parte destes fornecedores em relação à devolução destes resíduos, causada principalmente pela dificuldade em conseguir um carro para transporte. Conforme relatos, estes resíduos acabam sendo destinados, algumas vezes, aos sacos de recipientes do grupo A como "solução" de descarte.

Grupo D: ocorre somente a remoção dos resíduos para outro saco plástico de maior capacidade, o qual a higienizadora leva para proceder ao recolhimento. Como não há remoção diária dos sacos plásticos das lixeiras, este procedimento pode ser considerado inapropriado, visto que, a possibilidade de encontrar resíduos infectantes junto ao comum é grande. Sendo assim, ao realizar este ato, a higienizadora aumenta as chances de se contaminar.

Grupo E: a coleta destes resíduos é realizada pelas enfermeiras, e ocorre somente com o preenchimento quase total da caixa, não respeitando as normas estabelecidas pela RDC no 306/04 da ANVISA que preconiza a utilização de (2/3) do volume do recipiente. Após ser lacrada, a caixa é levada para o armazenamento externo, juntamente com as outras classes de resíduos, onde ficam aguardando a coleta externa.

\section{Armazenamento Temporário}

Schneider (2007) ao analisar os sistemas de gerenciamento dos RSS em Unidades Básicas de Saúde no Município de Caxias do Sul/RS, verificou que apenas 15,5\% das UBSs possuíam sala de resíduos, local considerado o mais adequado para o armazenamento interno. O restante das unidades armazenava em lugares de constante fluxo de pessoas e de fácil acesso, como banheiros, depósitos, lavanderias. Não obstante desta realidade, observou-se na UBS estudada a existência de um armazenamento temporário exclusivo para resíduos infectantes localizado na sala de expurgo e esterilização, onde foi verificado que este se constituía em um dispositivo de acondicionamento (lixeira) de maior porte, no qual ficavam dispostos os sacos de resíduos infectantes recolhidos dos consultórios. Dessa forma, o dispositivo destinado para tal finalidade não se enquadra nas especificações exigidas pela RDC nº 306/04 da ANVISA, 
que estabelece a presença de uma sala exclusiva para o armazenamento dos resíduos (BRASIL, 2004).

No caso dos resíduos químicos, o armazenamento temporário ocorre na farmácia da unidade. Considerando a RDC nº 306/04 da ANVISA e a resolução nº 358/05 do CONAMA que permite à inexistência de um armazenamento temporário para estabelecimentos de pequeno porte, devido à proximidade dos setores geradores ao local destinado à coleta (BRASIL, 2004; BRASIL, 2005). Assim, sugere-se que, após a remoção das lixeiras, os resíduos sejam transportados diretamente para o abrigo externo, bem como ocorre com os resíduos comuns e perfurocortantes.

\section{Armazenamento Externo}

A UBS conta com ambiente destinado para o armazenamento externo dos resíduos gerados na unidade. Esta área encontra-se protegida do sol, chuva, animais ou pessoas não autorizadas. Contudo, foi verificado que não há ventilação devido à inexistência de janelas e, além disso, a infraestrutura do ambiente para higienização é precária. Ademais, não há identificação deste local por meio de cores, símbolos e frases, além de outras exigências relacionadas à identificação de conteúdo e aos riscos específicos de cada grupo de resíduos.

Este ambiente também funciona como depósito e almoxarifado, servindo de local de armazenamento para latas de tinta, escadas, cadeiras e papelão. Durante o percurso de coleta, finalizado nessa sala, exige o trânsito das higienizadoras com RSS em meio à cozinha da unidade. Conforme a RDC nํㅜ 306/04 da ANVISA e a resolução n $^{\circ}$ 358/05 do CONAMA, a sala de armazenamento externo para os resíduos deve ser exclusiva para tal finalidade, e deve possuir, no mínimo, dois ambientes: um para armazenar coletores contendo resíduos dos Grupos A e E, e outro para guardar os recipientes que acondicionam resíduos pertencentes ao Grupo D (BRASIL, 2004; BRASIL, 2005). Além disso, o piso deste local deve ser impermeável, liso, e de fácil higienização. Tais exigências não foram observadas na sala de armazenamento da UBS estudada, haja vista que todos os resíduos do Grupo A, D e E são armazenados no mesmo ambiente. Em relação as caixas de perfurocortantes, verificou-se que estas ficam dispostas diretamente sobre o piso até a coleta externa.

\section{Coleta Externa}

Na UBS são realizados três tipos de coleta de resíduos: dos Grupos A + E (Infectantes e Perfurocortantes), do Grupo B (Químicos) e do Grupo D (comuns). Os resíduos comuns são dispostos na calçada enquanto aguardam a coleta da prefeitura. Os sacos que acondicionam esses resíduos são coletados três vezes na semana, em dias alternados. Como não foi implantada a coleta seletiva de materiais recicláveis nesta região, as caixas de papelão (único resíduo segregado) são colocadas na calçada para serem recolhidas por catadores autônomos.

Uma empresa terceirizada realiza a coleta dos resíduos infectantes e perfurocortantes semanalmente. Além disso, a mesma recolhe os RSS de todos os estabelecimentos de saúde de pertencentes à IES, e os encaminha a um município próximo a capital para posterior tratamento e destinação final. A coleta semanal é suficiente para a geração de resíduos na unidade, no entanto deve ser realizada periodicamente nos dias pré-estabelecidos, no intuito de evitar o acúmulo de resíduos. Segundo relatos, já foram presenciadas falhas na rotina de coleta. Com isso, os resíduos permaneceram por até 15 dias no local, abarrotando a bombona destinada a resíduos infectantes. Esse recipiente é recolhido manualmente e levado para o veículo coletor devidamente licenciado. Não há nenhum contato direto dos funcionários com os resíduos, uma vez que ocorre a troca da bombona cheia por outra vazia, devidamente higienizada, tornando a coleta rápida e segura. Os resíduos perfurocortantes acondicionados nas caixas são recolhidos e dispostos no veículo coletor.

Os medicamentos fora do prazo de validade são coletados pela Farmácia e pelo Hospital Escola. O pessoal responsável por esse processo não possui o devido treinamento, além de que o transporte ocorre em carros não licenciados para tal finalidade.

\section{Tratamento}

Resíduos pertencentes ao Grupo D são coletados pela prefeitura e não recebem qualquer forma de tratamento. Já os resíduos químicos líquidos passam por um processo de solidificação, mas também não são tratados.A empresa terceirizada realiza o tratamento dos resíduos pertencentes aos Grupos A e E. O processo utilizado é o tratamento térmico baseado na incineração dos resíduos, o qual objetiva minimizar a quantidade de resíduos gerada a ser disposta no aterro. Essa técnica exige um acompanhamento quase diário das emissões gasosas geradas pela queima dos resíduos tratados, da disposição final da cinza resultante da incineração e do lodo gerado pela lavagem dos gases (ELEUTÉRIO et al., 2008).

\section{Disposição Final}

Segundo a resolução $n^{0}$ 5/93 do CONAMA a incineração do resíduo do serviço de saúde é o meio de tratamento, embora não obrigatório mais indicado para o tratamento dos resíduos. São gerados no sistema de incineração efluentes gasosos, cinzas e escórias da câmara de incineração de resíduos, bem como efluentes líquidos gerados na atividade desse sistema de tratamento. As cinzas e escórias, em geral, contêm metais pesados em alta concentração e não podem, por isso, ir para aterros sanitários, sendo necessário um aterro especial para 
esses resíduos perigosos (ANVISA, 2006). Conforme Relata Naime et al. (2004), os componentes do Grupo D se assemelham aos resíduos domiciliares e recicláveis, com isso, podem ser destinados à coleta seletiva.

\section{Conclusões e Recomendações}

O estudo permite apontar a necessidade de implementação de políticas de gestão dos RSS na UBS vinculada a IES. Assim, a construção de um Plano de Gerenciamento de Resíduos de Serviços de Saúde (PGRSS) é fundamental e urgente, afim de normatizar todas as etapas do manejo dos resíduos e instrumentalizar os indivíduos envolvidos para que os riscos à saúde e ao ambiente sejam minimizados. A ferramenta de avaliação proposta pode ser utilizada como ponto de partida para a elaboração do PGRSS na unidade. A partir da realidade percebida, adotou-se de modo ordenado algumas ações que servirão de base para a implantação contínua PGRSS:

Estabelecer políticas ambientais dentro da UBS que instituam práticas de minimização dos resíduos;

Implantar recipientes de acondicionamento com tampa, e provida de pedal;

Realizar a separação dos resíduos recicláveis, buscando adaptação dos funcionários à futura implantação de coleta seletiva na região;

Deve-se projetar uma rota mais adequada para o transporte dos resíduos até o abrigo externo, visto que a rota atualmente seguida não é a mais indicada pelas normas legais;

Identificar visivelmente o armazenamento externo e destiná-lo a somente para tal finalidade;

Propiciar o envolvimento e participação dos funcionários, docentes e estudantes atrelando a eles a responsabilidade, co-responsabilidade e responsabilidade social, buscando uma maior contribuição na proposição de ações, a fim de realizar um gerenciamento mais eficaz;

Estabelecer instrumentos informativos para os funcionários e usuários da UBS, criando um manual de boas práticas em manejo dos resíduos sólidos;

Promover capacitação a higienizadora orientando sobre a importância do uso de Equipamentos de Proteção Individual - EPIs, além de mostrar os riscos a que ela está exposta ao manejar os RSS de maneira incorreta;

Por fim, a UBS deve contratar um técnico de nível superior, devidamente capacitado para elaborar, implantar e monitorar o PGRSS.

\section{Referências}

ABRELPE. Associação Brasileira de Empresas de Limpeza Pública e Resíduos Especiais. Panorama dos Resíduos Sólidos no Brasil. São Paulo, 2014. 120 p.
BARROS JÚNIOR, C.; AMANTHEA, E.; LAZARIN, F. B.; XAVIER, G. A.; TSUJIOCA, Y. D.; BELLI, R.; RODRIGUES, R.; DAMASCENO, J. W. Geração e caracterização dos resíduos de serviços de saúde em laboratório de análises clínicas de Maringá(PR). Acta Scientiarum. Technology, v.29, p.17-21, 2007.

BRASIL - ANVISA. Agência Nacional de Vigilância Sanitária. Manual de gerenciamento de resíduos de serviços de saúde - série A. Normas e Manuais Técnicos: Brasília, DF. 2006.

BRASIL- PNRS. Política Nacional de Resíduos Sólidos. Lei no 12.305, de 02 de agosto de 2010. Site do Palácio do Planalto, Brasília, DF, 2010. Disponível em:http://www. planalto.gov.br/ccivil_03/_ato2007-210/2010/lei/112305. htm. Acesso em: 29 abr. 2016.

BRASIL- ANVISA. Agência Nacional de Vigilância Sanitária. Manual de Gerenciamento de Resíduos de Serviço de Saúde. Brasília (Brasil): Ministério da Saúde, 2006. $182 \mathrm{p}$.

BRASIL. Senado Federal. Resolução noํㅡㄹ, de 1993 do CONAMA. Define os procedimentos básicos relativos ao gerenciamento de resíduos sólidos de serviços de saúde. Diário Oficial da República Federativa do Brasil, Brasília, DF, 31 ago. 1993. Seção 1, p. 12996.

BRASIL. Senado Federal. Resolução nํㅡㄹㅡ 283, de 2001 do CONAMA. Dispõe sobre o tratamento e destinação final dos resíduos sólidos. Diário Oficial da República Federativa do Brasil. Brasília; 01 out. 2001a. Seção I, p. 12996.

Resolução CONAMA no 358 de 29 de abril de 2005. Dispõe sobre o tratamento e a disposição final dos resíduos dos serviços de saúde e dá outras providências. Diário Oficial da República Federativa do Brasil (Brasília). 2005 maio 04.

Resolução do Diretório Colegiado da ANVISA no 306 de 07 de dezembro de 2004. Dispõe sobre o Regulamento Técnico para o gerenciamento de resíduos de serviços de saúde. Diário Oficial da República Federativa do Brasil (Brasília), 2004 dez 10.

CAMPOS, A. A. G. (org.) Apostila de Gerenciamento dos Resíduos de Serviços de Saúde: Programa Estadual de Controle de Infecção Hospitalar - Estado de Santa Catarina, Florianópolis, 1998.

CORRÊA, L. B; et al. O saber resíduos sólidos de serviços de saúde na formação acadêmica: uma contribuição da educação ambiental. In: Comunic, Saúde, Educ (Org.). Pelotas, 2005. p. 571-584 
CORRÊA L. B. Construção de políticas para a gestão dos resíduos em uma instituição de ensino superior na perspectiva da educação ambiental. 2009. $286 \mathrm{f}$. Tese (Doutorado em Educação Ambiental) - Programa de Pós-Graduação em Educação Ambiental, Universidade Federal do Rio Grande, Rio Grande. 2009.

ELEUTÉRIO, J. P. L; HAMADA, J.; PADIM, A. F. Gerenciamento eficaz no tratamento dos Resíduos de Serviços de Saúde - Estudo de duas tecnologias térmicas. In: ENCONTRO NACIONAL DE ENGENHARIA DE PRODUÇÃO, 28., 2008, Rio de Janeiro. Anais do Congresso Brasileiro de Engenharia de Produção, Rio de Janeiro: ABREPO, 2008. p.11.

FARIAS, L. M. M. (2005). Impasses e possibilidades do gerenciamento de resíduos de serviços de saúde no Brasil: um estudo de caso no Centro de Saúde Escola Germano Sinval Faria ENSP FIOCRUZ. Dissertação de Mestrado - Escola Nacional de Saúde Pública ENSP/ FIOCRUZ. Disponível em: http://arca.icict.fiocruz.br/ bitstream/icict/4893/2/836.pdf. Acesso em: 10 abr. 2016.

GIL, T. N. L; et al. Caracterização Qualitativa e Quantitativa dos Resíduos de Serviço de Saúde gerados na Irmandade Santa Casa de Misericórdia de São Carlos, SP. In: CONGRESSO BRASILEIRO DE ENGENHARIA SANITÁRIA E AMBIENTAL, 24., 2007, Belo Horizonte. Anais do Congresso Brasileiro de Engenharia Sanitária Ambiental, Belo Horizonte: Associação Brasileira de Engenharia Sanitária e Ambiental, 2007. p.7.

LAKATOS, E. M.; MARCONI, M. A. Fundamentos de metodologia científica. São Paulo: Atlas, 1991. 270 p.

MARCOS, E. S. Da observação participante a pesquisaação: uma comparação epistemológica para estudos em administração. 2001. Disponível em: www.angelfire. $\mathrm{com} / \mathrm{ms} /$ tecnologia/pessoal/facef_pesq.pdf. Acesso em: 29 jun. 2013.

MOREIRA, A. M. M. Gerenciamento dos resíduos de serviço de saúde: um desafio para as unidades básicas de saúde. 2012. 199 f. Dissertação (Mestrado em Saúde Publica) - Faculdade de Saúde Pública. São Paulo, Universidade de São Paulo, São Paulo. 2012.

MORESI, E. Metodologia da Pesquisa, Brasília, 2003,108 p.

NAIME, R.; SARTOR, I.; GARCIA, A.C. Uma abordagem sobre a gestão de resíduos de serviços de saúde. Rev. Espaço para a saúde, Londrina, v.5, n.2, p. 17-27, jun. 2004.
OLIVEIRA, L.L.Estudo do Gerenciamento dos Resíduos dos Serviços de Saúde na Atenção Básica em Campina Grande-PB. 2012. 131 f. Dissertação (Mestrado em Recursos Naturais)- Universidade Federal de Campina Grande, Campina Grande. 2012.

PORTAL BRASIL. Disponível em:http://www.brasil.gov. $\mathrm{br} /$ sobre/saude/atendimento/unidades-basicas-de-saude. Acesso em: 10 abr. 2016.

SCHNEIDER, V.E. (org). Manual de gerenciamento de resíduos sólidos em serviços de saúde. $2^{\underline{a}}$ ed. Caxias do Sul: Ed. rev. e ampl: EDUCS, 2004.

SCHNEIDER, V. E, et al. Gerenciamento de Resíduos Sólidos de Serviço de Saúde em Unidades Básicas de Saúde. In: CONGRESSO BRASILEIRO DE ENGENHARIA SANITÁRIA E AMBIENTAL, 24., 2007, Belo Horizonte. Anais do Congresso Brasileiro de Engenharia Sanitária Ambiental. Belo Horizonte: Associação Brasileira de Engenharia Sanitária e Ambiental, 2007. p.7.

SERAPHIM, C. R. U. M. Abordagem dos Resíduos de Serviços de Saúde (RSS) na Formação Profissional dos Auxiliares e Técnicos em Enfermagem de Araraquara-SP. Dissertação (Mestrado em Desenvolvimento Regional e Meio Ambiente). Araraquara: Centro Universitário de Araraquara/UNIARA; 2010. 154 p.

TAKAYANAGUI, A.M.M. Gerenciamento de Resíduos de Serviços de Saúde. In: PHILLIPI JR, A.(Ed.). Saneamento saúde e ambiente: fundamentos para um desenvolvimento sustentável. Rio de Janeiro: Manole, 2005.p.323-374. 